\title{
ULTRASTRUCTURAL DEMONSTRATION OF NADPH OXIDASE ACTIVITY IN KUPFFER AND ENDOTHELIAL GELLS USING AN ISOLATED LIVER PERFUSION SYSTEM -COMPARISON BETWEEN ICR/D-STRAIN AND JCL: WISTAR-STRAIN RATS-
}

\author{
Nobuo IHARA and Shuji FUNO* \\ Department of Pathology, Kansai Medical University, Fumisono-cho, Moriguchi \\ City, Osaka 570; Tsumura Research Institute for Pharmacolog $y^{*}$. \\ Tsumura Juntendo Co. Ltd., Ami-cho, Inashiki-gun, \\ Ibaraki 300-11
}

Received for publication August 10, 1984 and in revised form December 20, 1984

\begin{abstract}
In order to cytochemically demonstrate the $\mathrm{NADPH}$ dependent $\mathrm{H}_{2} \mathrm{O}_{2}$ generation system in the sinusoidal lining cells of the liver, the authors applied the modified method of Briggs et al. (5) to an isolated liver perfusion system devised by Sugano et al. (21). The rat liver was perfused with the reaction medium containing $40 \mathrm{mg}$ NADPH, $40 \mathrm{mg} \mathrm{CeCl} \mathrm{CH}_{3} 7 \mathrm{H}_{2} \mathrm{O}$ and $2 \mathrm{mg}$ glucose in $100 \mathrm{ml}$ of 0.1 M tris-maleate buffer solution ( $\mathrm{pH} 7.4$ ), continuously supplied with a gas mixture $\left(95^{\circ}{ }_{0} \mathrm{O}_{2}\right.$ and $\left.5 \% \mathrm{CO}_{2}\right)$. With respect to the specificity of the reaction, the in situ localization, and the amount of reaction products, adequate results were obtained with this system. Thus, the activity in the sinusoidal lining cells was compared between livers of the Jcl:Wistar-and the ICR/d-strain rats affected with spontaneously occurring cataracts and dermatitis.

Both Kupffer and endothelial cells showed conspicuous reactivity. A specific and significant reaction product was observed, adherent to the plasma membrane, on the external cell surface, including that of invaginated portions or coated pits. Furthermore, it was also noted on the internal surface of phagocytic vacuoles or coated vesicles. Comparing the two strains of rat, a much higher reactivity was shown in the liver of ICR/d-rat, suggesting that a defensive activity may be enhanced in the sinusoidal area to compensate for constitutional defects such as immunological disorders inherent in the ICR/dstrain.
\end{abstract}

A free radical generation system (hydrogen peroxide and superoxide etc.) in leukocytes and macrophages plays an important role in bactericidal or detoxifying activities through phagocytosis $(1,3,6,15,17)$. For the activity of $\mathrm{NAD}(\mathrm{P}) \mathrm{H}$ dependent, cyanide insensitive $\mathrm{H}_{2} \mathrm{O}_{2}$ generation ( $\mathrm{NAD}(\mathrm{P}) \mathrm{H}$ oxidase) $(1,16,18,22)$, a cytochemical technique for localization of $\mathrm{H}_{2} \mathrm{O}_{2}$ generated was developed by Briggs et al. (5). Recently, this method was also applied to the demonstration of plasma-membrane associated $\mathrm{NAD}(\mathrm{P}) \mathrm{H}$ oxidase activity in pulmonary macrophages by Hirai et al. (10).

Abbreviations in this paper: NADPH, beta-Nicotinamide adenine dinucleotide phosphate, reduced form; PM, Standard perfusion medium; RM, Standard reaction medium; LPS, Lipopolysaccharide. 
This oxidative activity might also be functioning in the resident macrophages, such as the Kupffer cells, which play an important role in the sinusoidal lumen of the liver. In order to evaluate this possibility, the authors modified the method of Briggs et al. (5), and applied it to an isolated liver perfusion system devised by Sugano et al. (21) for ultrastructural detection of the specific reaction. Reaction products were found on the plasma membrane of the Kupffer cells as well as on the endothelial cells under conditions in which the histological and cytological architecture was well maintained.

This report is concerned with the specificity of reaction in this system, reactive cell types and sites at the ultrastructural level, with particular emphasis on the pathological findings seen in the ICR/d-strain rat.

\section{MATERIALS AND METHODS}

Experimental animals

(1) Male rats of ICR/d-strain aged 2 to 3 months were used. This strain of rat (11-13), which has spontaneously occurring cataract and dermatitis were bred and maintained in our laboratory under conventional conditions, having free access to food and water.

(2) Rats of $\mathrm{Jcl}$ : Wistar strain of the same sex and age were uscd after being reared under the same conditions for at least one week after purchase.

Each experimental group consisted of 10 to 16 animals. However, for examination of the specificity of the reaction, mainly the $I C R / d$-strain rats were used, because of the higher reactivity in their sinusoidal lining cells.

Methods

1. Pre-perfusion stage

For the present experiment, the liver perfusion system (Sugano et al.) (21) was applied, with a hemoglobin-free medium (Fig. 1). Procedures of liver extirpation

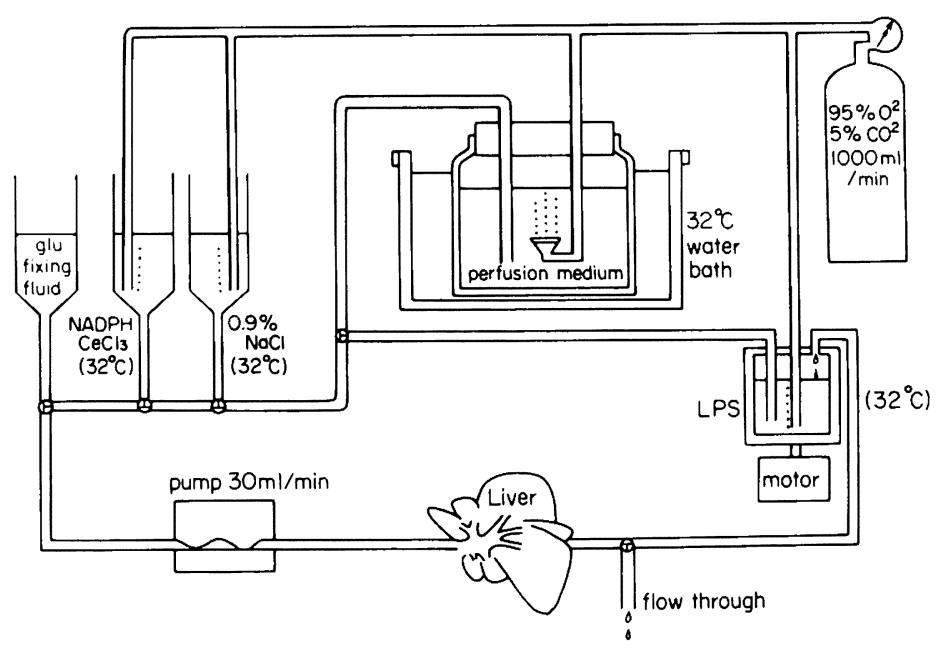

Fig. 1. Scheme of outline of liver perfusion system used in this experiment. 
and its setting to the perfusion apparatus have been described in detail by Sugano et al. (21) and by Funo (8).

The composition of the standard perfusion medium (PM) is shown in Table 1, as follows.

TABLE 1. Composition of the standard perfusion medium $(P M)$

$\begin{array}{lr}\mathrm{KCl} & 5.9 \mathrm{mM} \\ \mathrm{MgCl}_{2} & 1.2 \mathrm{mM} \\ \mathrm{NaH}_{2} \mathrm{PO}_{1} & 1.2 \mathrm{mM} \\ \mathrm{Na}_{2} \mathrm{SO}_{4} & 1.2 \mathrm{mM} \\ \mathrm{CaCl}_{2} & 2.5 \mathrm{mM} \\ \mathrm{NaCl}_{\mathrm{NaHCO}} & 115.0 \mathrm{mM} \\ \text { Glucose } & 25.0 \mathrm{mM} \\ & 10.0 \mathrm{mM}\end{array}$

The PM was kept at $32^{\circ} \mathrm{C}$ and supplied continuously with a fine foamy gas mixture $\left(95 \% \mathrm{O}_{2}\right.$ and $\left.5 \% \mathrm{CO}_{2}\right)$. In each experiment, pre-perfusion with the standard PM was performed for 30-40 min, because it has been found that the extirpated liver is restored to its physiological state after such a procedure (21).

2. Detection stage

(1) Perfusion procedure with the standard reaction medium (RM).

These procedures are described in sequential order as follows:

All solutions were prepared just before use, and supplied continuously with the gas mixture.

a) After pre-perfusion, the sinusoidal lining cells were stimulated through a closed circulation system with the standard PM containing lipopolysaccharide B of Escherichia coli (LPS, 055:B6, Difco Lab. Detroit Mich.) at a concentration of $10 \mathrm{mg} / 100 \mathrm{ml}$ for $10 \mathrm{~min}$.

b) After a rinsing perfusion with a physiological salt solution, the liver was perfused with the standard RM shown in Table 2, as follows.

TABLE 2. Composition of standard reaction medium $(R M)$

\begin{tabular}{lr}
$\mathrm{NADPH}$ & $40 \mathrm{mg}$ \\
$\mathrm{CeCl}_{3} \cdot 7 \mathrm{H}_{2} \mathrm{O}$ & $40 \mathrm{mg}$ \\
Glucose & $2 \mathrm{mg}$ \\
\multicolumn{2}{c}{ in } \\
$0.1 \mathrm{M}$ tris-maleate buffer \\
$100 \mathrm{ml}(\mathrm{pH} 7.4)$
\end{tabular}

Note: 3-amino-1,2,4,triazole, an anti-catalase agent was not used in this RM, because, on exposure to the agent, the liver swelled remarkably and thereby blocked further perfusion.

Perfusion time was about $3 \mathrm{~min}$ and $20 \mathrm{sec}(100 \mathrm{ml}$ of the $\mathrm{RM}$ was used as a whole) in the case of ICR-rats and about $6 \mathrm{~min}$ and $40 \mathrm{sec}(200 \mathrm{ml}$ as a whole) in the case of $\mathrm{Jcl}:$ Wistar rats respectively.

c) Rinsing perfusion with a physiological salt solution.

d) Fixing perfusion with $2.5 \%$ glutaraldehyde in $0.1 \mathrm{M}$ cacodylate buffer (pH 7.4) for 2 to $3 \mathrm{~min}$.

Tissue blocks of about $1 \times 1 \mathrm{~mm}^{3}$ were obtained from the right central lobe 
immediately after the final perfusion, immersed again in the same fixative for an additional $30 \mathrm{~min}$, post-fixed with $1 \% \mathrm{OsO}_{4}$ in $0.1 \mathrm{M}$ veronal buffer $(\mathrm{pH} \mathrm{7.4)}$ after rinsing with $0.1 \mathrm{M}$ cacodylate buffer solution and processed routinely for electron microscopic observation. For preparation of ultrathin sections, periportal areas of the hepatic lobule were selected.

(2) Reactivity tests under a few abnormal conditions

The following two tests were performed in order to observe (a) a strict oxygen dependency of this reaction system and (b) a substantial stimulation effect of LPS.

a) Cutting off the supply of the gas mixture during the period when the liver was perfused with the RM.

b) Omission of the stimulation procedure with LPS.

(3) Specificity tests

A series of control experiments was performed in order to gain some insight into the specificity of the reaction.

a) Perfusion with the reaction medium (prepared at $\mathrm{pH}$ 7.4) from which the substrate (NADPH) or $\mathrm{CeCl}_{3}$ was eliminated.

b) Pre-fixation before exposure to the RM through perfusion with $2.5 \%$ glutaraldehyde in $0.1 \mathrm{M}$ cacodylate buffer for $30 \mathrm{sec}, 1$ or $2 \mathrm{~min}$.

c) Addition of catalase (manufactured by Sigma Chem.) to the standard $\mathrm{RM}(\mathrm{pH} \mathrm{7.4)}$ at concentrations of 10,20 and $30 \mathrm{mg} / 100 \mathrm{ml}$.

d) Addition of $\mathrm{KCN}$ to the standard $\mathrm{RM}$ ( $\mathrm{pH} 7.4-7.6$ ) at concentrations of 10,20 and $40 \mathrm{mg} / 100 \mathrm{ml}$.

e) Perfusion with a buffered medium containing fine cerium precipitate (passed through 45 micron milipore filter), previously prepared by artificial addition of $\mathrm{H}_{2} \mathrm{O}_{2}$ to the $\mathrm{CeCl}_{3}$ solution. The detailed procedures have been described by Funo (8).

\section{RESULTS}

1. Activity findings in the $I C R / d$-strain

(1) $\mathrm{H}_{2} \mathrm{O}_{2}$ generation and localization in the standard procedures

Both the Kupffer and the endothelial cells showed conspicuous reactivity.

In the Kupffer cells, the external surface of the plasma membrane including the invaginated regions or coated pits, and more notably the side bordering on the sinusoidal lumen, was covered widely with a layer of cerium precipitate (Fig. 2). In some regions, this layer was continuous and in other regions it was discontinuous. Additionally, phagocytic vacuoles as well as the apparent profiles of surfaceconnected channels were lined with the reaction products in a fashion similar to that seen on the outer cell surface. However, vacuoles containing a large or small amount of LPS showed little or only scattered reaction products on their internal surface (Figs. 2, 3). Free reaction products, which did not adhere to the plasma membrane, were also observed intermittently in the sinusoidal lumen, especially in the vicinity of the cell border, and also in the pit-like or invaginated portions, and phagocytic vacuoles (Fig. 3). Golgi apparatus, endoplastic reticulum, mitochondria and other subcellular structures showed no reaction products.

In the endothelial cells, the external surface of the cell membrane, pit-like portions and coated pits, and the internal surface of coated or pinocytic vesicles 
showed a conspicuous layer of the precipitous deposits similar to that seen in the Kupffer cells (Fig. 4a). Especially on the external surface of coated pits, a notable reaction could be seen, frequently displaying a localized thick layer of cerium precipitate (Fig. 4b). Another notable finding was that, when the endothelial cells or endothelial cells and a Kupffer cell were closely connected with each other, a conspicuous and continuous deposit of the reaction products was observed on the extensive interface of the cell membranes (refer to Fig. 5).

(2) Reactivity under a few abnormal conditions

a) When the supply of the gas mixture was stopped during perfusion of the standard RM, the reactivity was strongly suppressed in both cells of the sinusoidal lining so that almost no precipitate could be seen (Fig. 6).

b) When the stimulation procedure with LPS was omitted, the reaction products showed a significant decrease at the reactive sites of both cell types, although a weak or moderate precipitation was observable (Fig. 7).

(3) Examination for specificity of the reaction

a) When $\mathrm{CeCl}_{3}$ was eliminated from the standard $\mathrm{RM}$, almost no reaction could be seen.

When the substrate (NADPH) was eliminated from the standard RM, the amount of cerium precipitate was dramaticaly reduced, showing only slight deposition in the normally reactive sites (Fig. 8).

It is therefore clear that the generation of reaction products is strongly dependent on the presence of exogenous NADPH.

b) Exposure to glutaraldehyde before perfusion with the RM resulted in total elimination of reaction products from the cell (Fig. 9). At the same time, almost no precipitate was observed, while otherwise it would have been seen free in the sinusoidal lumen, cellular cavities or phagocytic vacuoles.

c) When catalase was included in the standard RM at concentrations of 20 or $30 \mathrm{mg} / \mathrm{dl}$, cerium precipitation was almost completely suppressed (Fig. 10). At a concentration of $10 \mathrm{mg} / \mathrm{dl}$, only some areas showed a reduced amount of reaction products.

d) When KCN was included in the RM at concentrations of 10 or $20 \mathrm{mg} / \mathrm{dl}$, no notable inhibition occurred. Even when the concentration was increased to

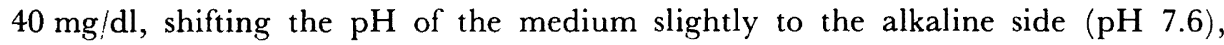
there was almost no interferance with the generation of precipitate (Fig. 11).

e) The possibility of a preferential binding of reaction products to the Kupffer or the endothelial cells was investigated by perfusing with the cerium medium already precipitated by prior addition of $\mathrm{H}_{2} \mathrm{O}_{2}$, instead of normal perfusion with the RM. The result was that reaction products did not adhere closely and evenly to the cell membrane of the normally reactive sites, an appearance quite distinct from that with the proper perfusion (Fig. 12).

2. The activity findings in the $\mathrm{Jcl}$ : Wistar-rat compared with those in the ICR/d-rat

Under standard experimental conditions, it was found that both cell types of the hepatic sinusoid in Jcl: Wistar rats showed a comparatively weak reaction. Therefore, the liver of this strain was perfused with an additional $100 \mathrm{ml}$, plus $100 \mathrm{ml}$ of the RM and the duration was doubled. As a result, generation of precipitate was significantly increased to a level largely similar to that seen in the livers of $\mathrm{ICR} / \mathrm{d}$-strain. 
Abbreviations used in the following figures: $\mathrm{S}$, sinusoid; $\mathrm{N}$, nucleus, $\mathrm{V}$, phagocytic vacuoles; $\mathrm{P}$, coated pits; K, Kupffer cell; E, endothelial cell; L, liver cell.

Fig. 2. Kupffer cell of the ICR-rat liver, perfused with perfusion medium containing LPS and then with standard reaction medium (Standard procedures). Double-stained with uranyl acetate and lead citrate. A layer of reaction product (arrowheads) is shown extensively onthe external cell surface including invaginated portions. In phagocytic vacuoles containing a moderate or small amount of LPS (small arrows), no clear reaction is noted. However, in the coated-pits or invaginated portions, coexistence of the precipitate with LPS can be seen (large arrow). $\times 27,000$

Fig. 3. Kupffer cell of the ICR-rat liver, perfused according to the standard procedures. Free reaction product ( $\mathrm{F}$ mark) is seen in the sinusoidal lumen and also in the invaginated portions or phagocytic vacuoles. At the same time, a layer of precipitate is seen on the outer cell surface or inner surface of the vacuoles (arrowheads), adhering to the plasma membrane. Note the presence of membrane-like LPS (small arrows) in the sinusoidal lumen as well as in the phagocytic vacuoles. $\times 27,200$

Fig. 4a. Endothelial cells of the ICR-rat liver, perfused according to the standard procedures. Extensive deposits of reaction product are seen on the external cell surface (arrowheads). A relatively thick layer of the precipitate is observed on the outer surface of the coated pits. 19,100

FIg. 4b. This photograph shows a high power view of an endothelial cell of the ICR-rat liver, perfused according to the standard procedures. There are coated pits and vesicles (arrowheads) which exhibit an especially thick layer of the precipitate on their external or internal surface. 59,200

Fig. 5. This specimen shows endothelial cells and a Kupffer cell of the Jcl: Wistar rat liver, perfused according to the standard procedures. The Kupffer cell, located nearly at the center of the photograph, contains many organelles (LPS-containing phagosomes are not seen in this section). On the extensive interface between the membranes of those which are in close contact with each other, a conspicuous and continuous deposit of reaction products can be seen (arrows). This is one of the characteristic findings obtained in this histochemical experiment. $\therefore 18,600$

Fig. 6. Kupffer cells of the ICR-rat liver, perfused according to the standard procedures, but with the gas mixture being shut off during the period of perfusion with the reaction medium. No fixed or free deposits are observed. $\quad 9,500$

Fig. 7. Kupffer cells of the ICR-rat liver, perfused with the standard RM, but LPS stimulation procedure was omitted. Only slight deposits occur on the external surface as shown by the arrowheads. $\quad 5,800$

Fig. 8. Kupffer cell of ICR-rat liver, perfused with RM containing no substrate (NADPH). A relatively small amount of deposit is present only in a few vacuolar or invaginated structures of this cell as shown by the arrows. No reaction products are seen on the external surface. 19,500

FIG. 9. Kupffer and endothelial cells of ICR-rat liver, exposed to glutaraldehyde for 30 min before perfusion with the standard RM. No reaction products are observable at any reactive sites of the two cell types. $\quad 7,800$

FIG. 10. Endothelial cell of the ICR-rat liver, perfused with RM containing catalase at a concentration of $20 \mathrm{mg} / \mathrm{dl}$. Reaction products are not seen in the normally reactive sites, for example, in the coated pits shown by the arrowheads. $\quad \times 19,000$

FIg. 11. Kupffer cells of ICR-rat liver, perfused with the RM containing KCN at a concentration of $40 \mathrm{mg} / \mathrm{dl}$. Even in this condition numerous reaction products are found on the external surface as shown by the arrowheads. $\times 18,800$

FIG. 12. This specimen shows the Kupffer cell and the sinusoidal lumen of a liver of the ICR-rat, perfused with a buffered medium containing fine cerium precipitates prepared artificially. The precipitates, which are seen in a cluster in this area, never show any tendency to adhere to the cell membrane, although they are partially phagocytized. $\times 15,800$

Fig. 13. Kupffer cell of the Jcl:Wistar rat liver, perfused according to the standard procedures. The reaction products are seen only in the intracytoplasmic portions of this cell, such as deep cavities or invaginated channel structures and/or phagocytic vacuoles rather than on the external surface as shown by the arrows. $\times 13,600$ 


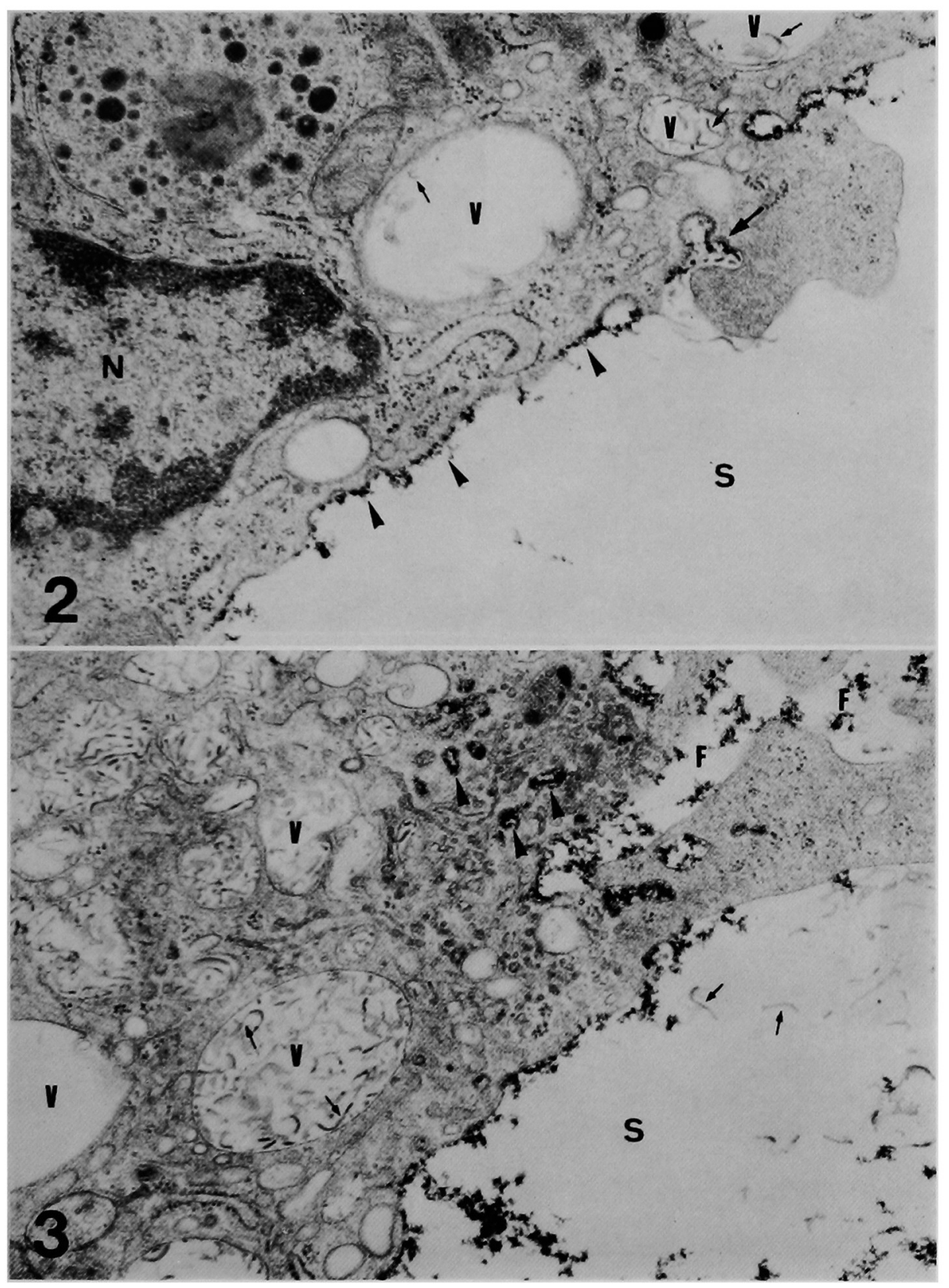




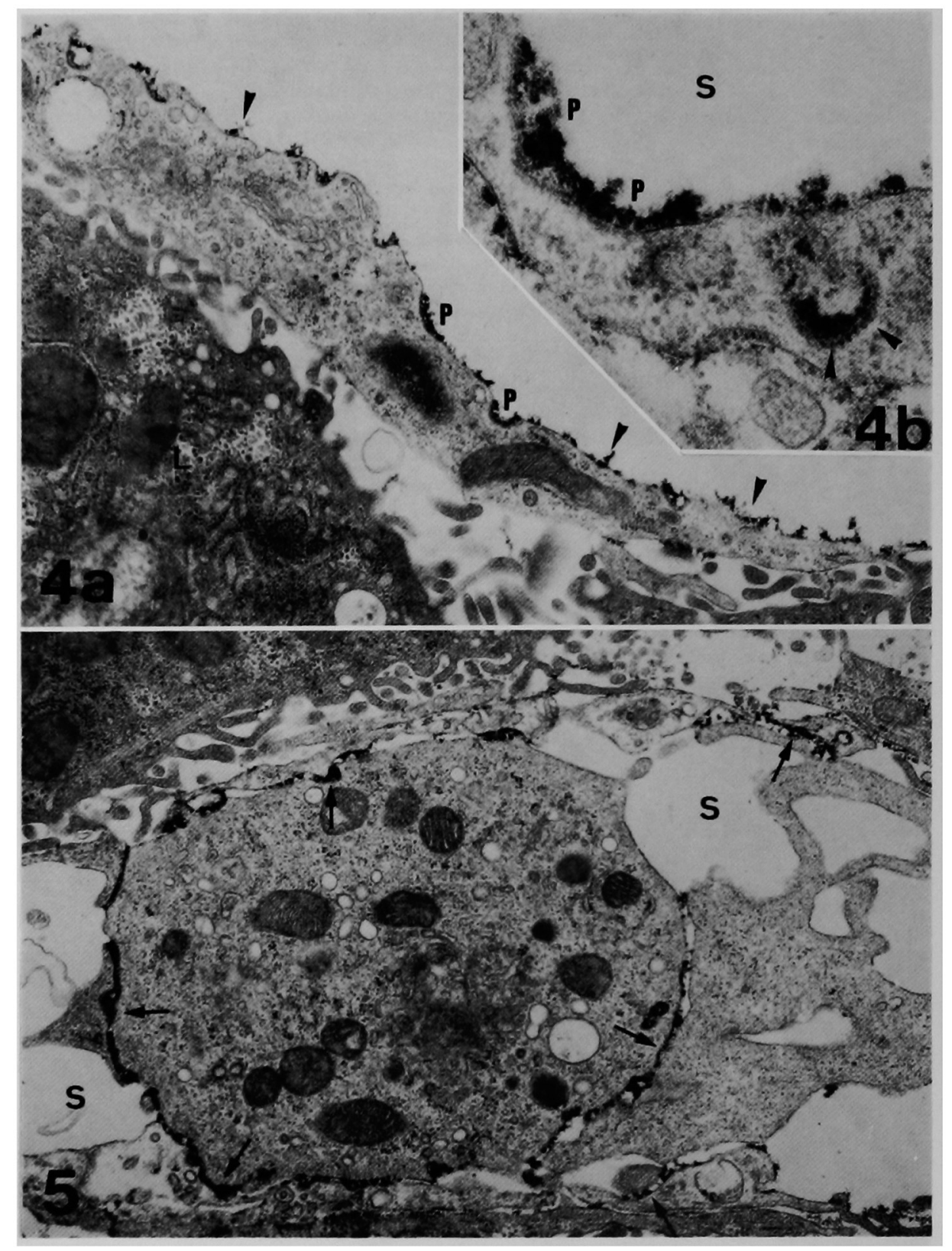




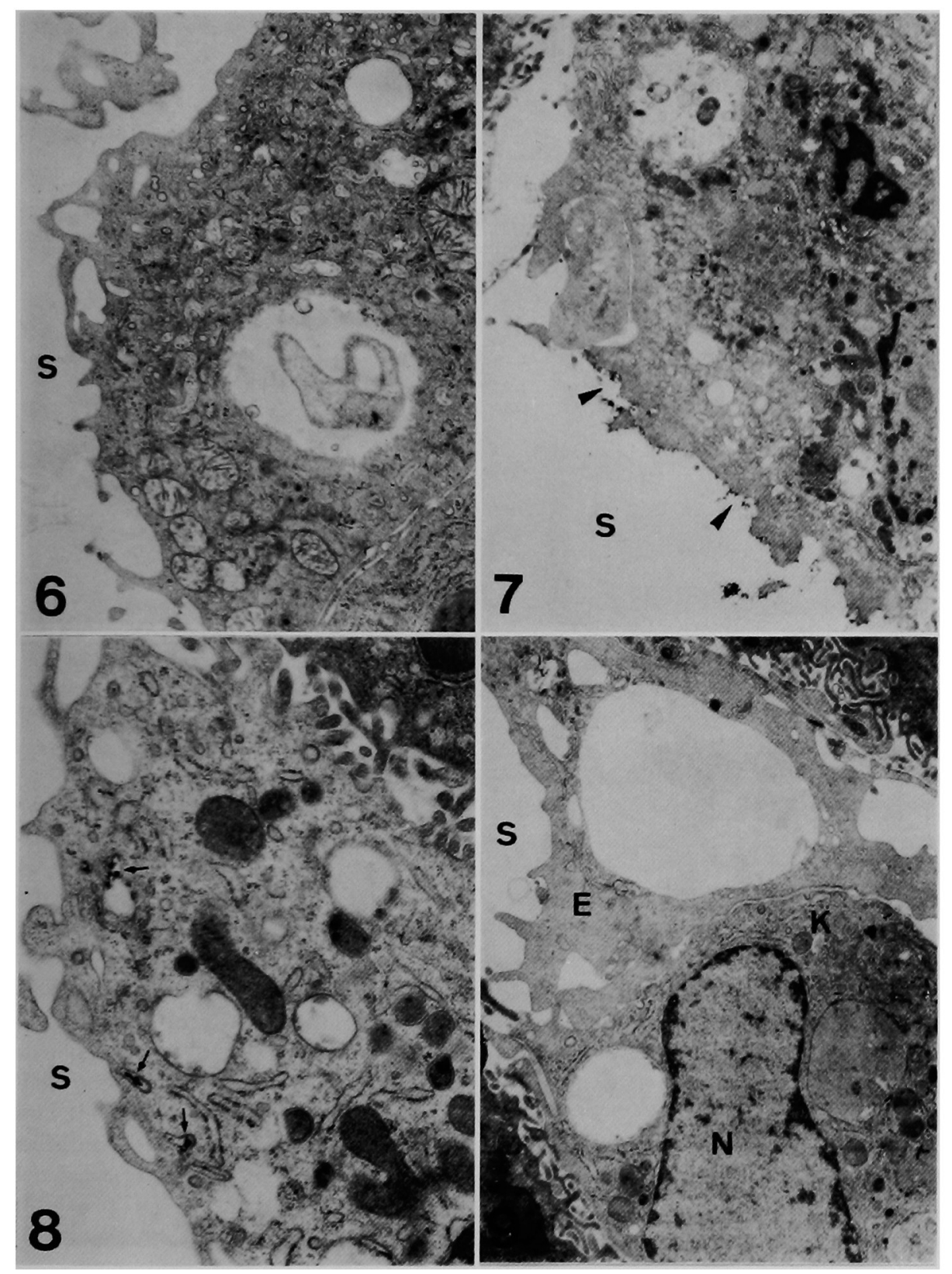




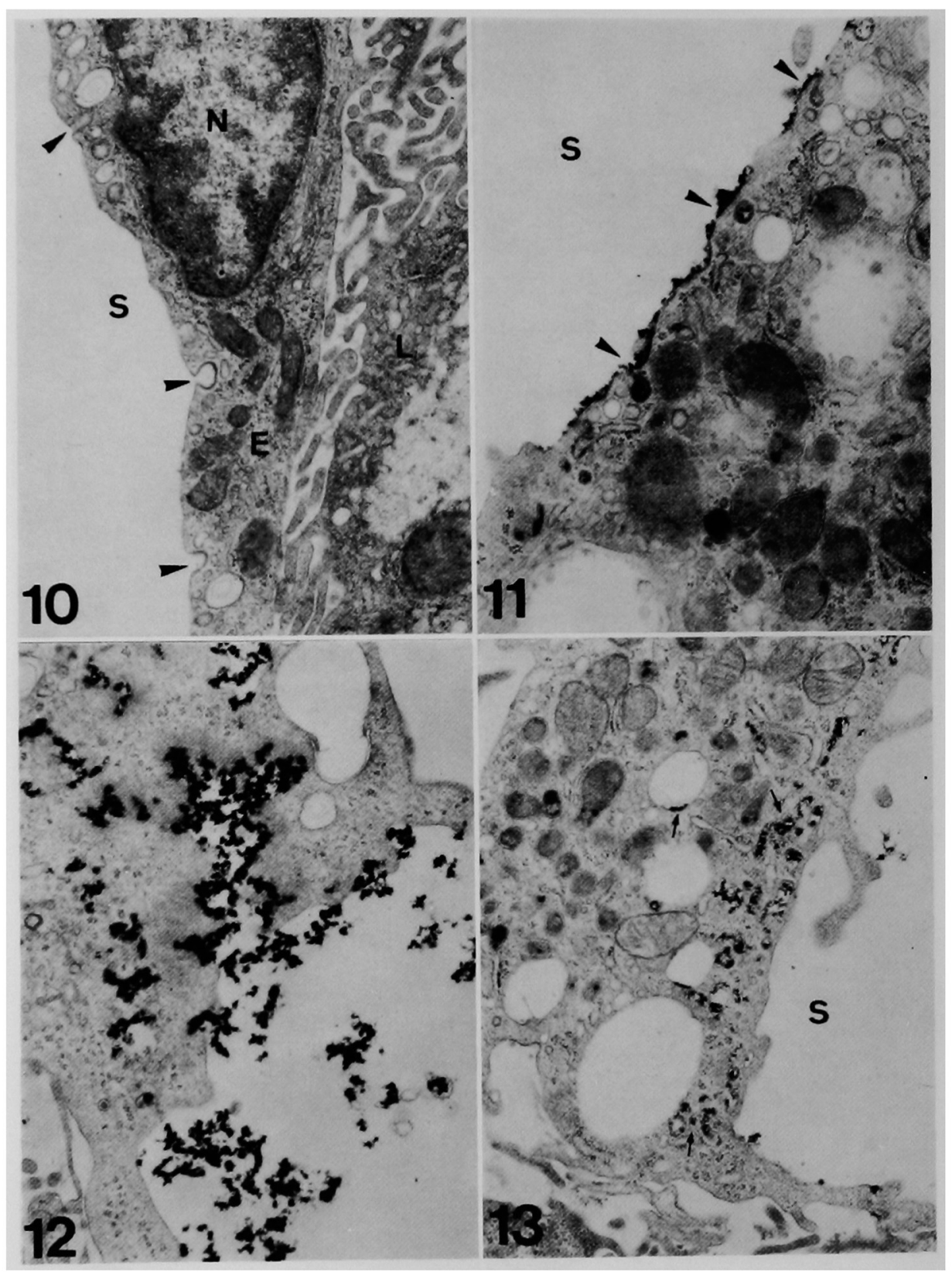




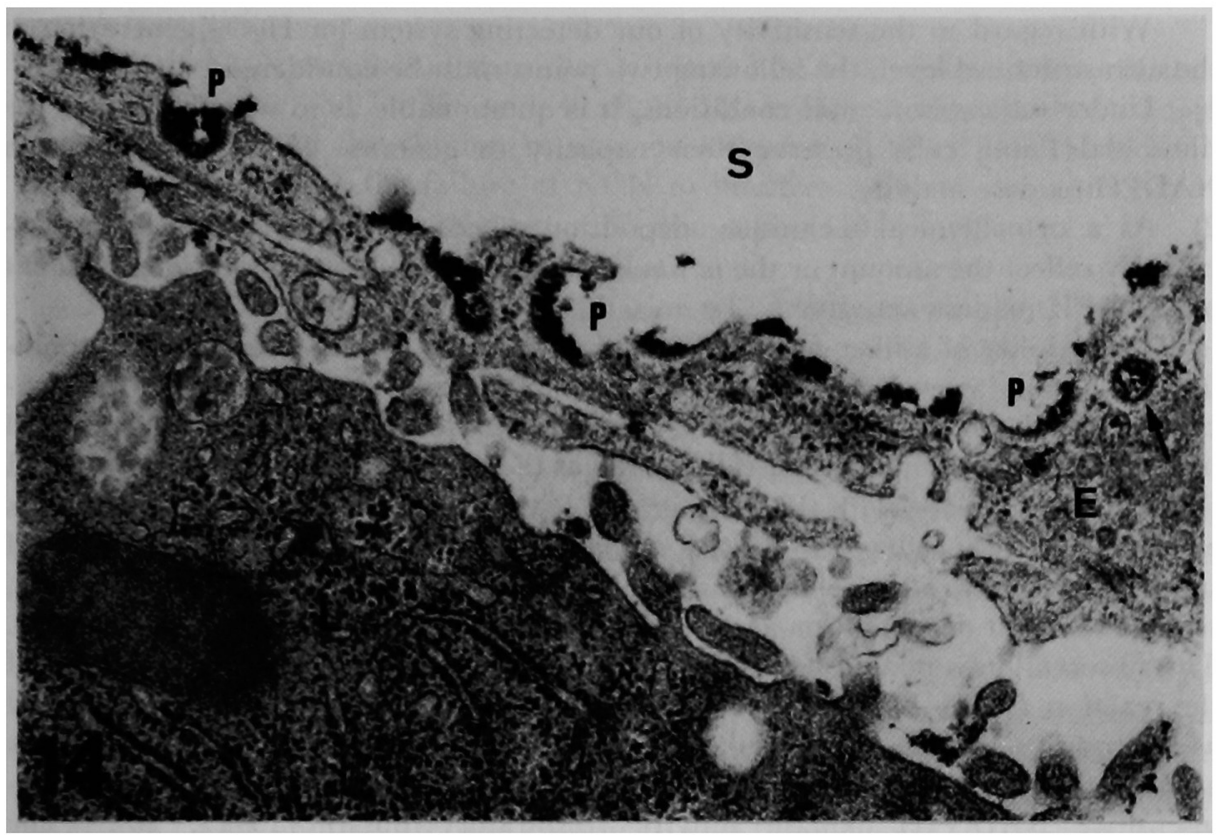

Fig. 14. Endothelial cells of the Jcl:Wistar-rat liver, perfused according to the standard procedures. A thick layer of deposit is seen on the external cell surface, although it is moderately discontinuous. Note a conspicuous reaction on the membrane surface of the coated pits and vesicle (arrow). $\times 39,600$

When the stimulation procedure with LPS was omitted, reaction products were significantly decreased, providing a finding similar to that in the ICR/d-strain under the same conditions. In order to observe the duration of the stimulatory effect of LPS, a 20 min perfusion procedure with the PM was added after the stimulation procedure with LPS; such effect of LPS on the precipitation of reaction products was almost completely abolished (preliminary data).

With regard to details as to the reactivity shown by each cell type, characteristic findings were as follows: Kupffer cells frequently had deposits of cerium precipitate only in the intracytoplasmic areas such as deep cavities, invaginated channel structures and/or phagocytic vacuoles rather than on the external cell surface. This precipitation may have occurred in situ, or have already formed on the surface and then quickly internalized or phagocytized (Fig. 13). As for the endothelial cells, no difference between the two strains was observed in the amount and/or the localization of the reaction when the experiment was performed under such conditions as described above (Figs. 5, 14).

\section{DISCUSSION}

The present experiment presents strong evidence that the $\mathrm{H}_{2} \mathrm{O}_{2}$ generation system plays a substantial role in the region of the hepatic sinusoid and additionally, that both cell types, the Kupffer cells and the endothelial cells in this area are equally involved. 
With regard to the sensitivity of our detecting system for $\mathrm{H}_{2} \mathrm{O}_{2}$ generation at the ultrastructural level, the following two points must be considered.

1) Under the experimental conditions, it is questionable as to whether or not the sinusoidal lining cells preserve their capacity to generate $\mathrm{H}_{2} \mathrm{O}_{2}$ dependent on NADPH oxidase activity.

2) As a cytochemical technique, deposition of cerium precipitate may not accurately reflect the amount or the in situ localization of $\mathrm{H}_{2} \mathrm{O}_{2}$ generation dependent on NADPH oxidase activity.

Availability of a liver perfusion system employing a hemoglobin and albuminfree medium, was evaluated by Sugano et al. (21) from the biochemical, pharmacological and ultrastructural aspects. We also confirmed that the morphological integrity of the sinusoidal lining cells as well as the hepatocytes were well maintained through the perfusion with the PM and the RM. Furthermore, as revealed in this experiment, both cell types showed a marked negative response to the reduced supply of oxygen, although damage at the ultrastructural level due to hypoxia, such as vacuolar degeneration and/or mitochondrial swelling etc. were not observed. This observation is related not only to cellular viability but also to the specificity of the reaction $(7,15-17)$, for it has been reported that endophagocytosis (as well as appropriate soluble or particulate stimuli to the cell membrane $(9,15)$ ) evokes a marked increase in oxygen consumption due to the enhancement of cyanideinsensitive $\mathrm{NAD}(\mathrm{P}) \mathrm{H}$ oxidase activity (respiratory burst) $(15-17,20)$. The positive response to LPS stimulation provides further evidence for the reaction specificity.

Next, we will comment on the constituents of the standard RM. In our experimental system, 3-amino-1,2,4-triazole was eliminated from the complete medium proposed by Briggs et al. (5) for the reason described previously. However, so far as this perfusion system is concerned, this did not affect the reactivity or its specificity and on the contrary, only $3 \mathrm{~min}$ or more was required for adequate generation of precipitate in the case of $I C R / d$-rat strain.

On the other hand, the $\mathrm{Jcl}$ :Wistar rats required a twofold amount of perfusion medium (about $6 \mathrm{~min}$ and $40 \mathrm{sec}$ ) for evoking a similar reactivity level. This was perhaps due to their comparatively low level of reactivity or sensitivity to LPS stimulation, though a comparatively high $\mathrm{H}_{2} \mathrm{O}_{2}$-degrading potential (such as catalase activity etc.) inherent in this strain should not be precluded.

Specificity was further examined by the following test:

Effects of glutaraldehyde

A $30 \mathrm{sec}$ perfusion with $2.5 \%$ glutaraldehyde solution completely abolished the cerium precipitation not only on the membrane surface but also in the lumen, be it sinusoidal or intracytoplasmic. This shows a higher sensitivity of the reaction to pre-fixation.

Substrate $(N A D P H)$ dependence

When $\mathrm{NADPH}$ was eliminated from the RM, the amount of cerium precipitation was markedly reduced in all reactive sites including the sinusoidal lumen, so that only a slight deposition appeared on the membrane surface. It is clear that the formation of reaction product is strongly dependent on the presence of exogenous NADPH $(2,5,16,18,22)$, whereas occurrence of a slight precipitation suggests the possibility that endogenous NADPH may participate in the reaction. 


\section{Cyanide insensitivity}

Even if $\mathrm{KCN}$ was included in the standard $\mathrm{RM}$ at a concentration of $10 \mathrm{mg}$ $(1.54 \mathrm{mM}), 20 \mathrm{mg}(3.07 \mathrm{mM})$ and $40 \mathrm{mg} / \mathrm{dl}(6.15 \mathrm{mM})$, both cell types showed similar amounts and distribution of reaction products to the RM lacking KCN. This is consistent with the failure of KCN to interfere with the respiratory burst associated with phagocytosis or membrane stimulation $(15,17,20)$.

Effect of catalase on generation of reaction products

To further confirm if cerium precipitation was dependent on $\mathrm{H}_{2} \mathrm{O}_{2}$ generation, catalase was added to the standard RM at a concentration of $10 \mathrm{mg}, 20 \mathrm{mg}$ or $30 \mathrm{mg} / \mathrm{dl}$. The results showed that cerium precipitation is indeed due to a reaction with $\mathrm{H}_{2} \mathrm{O}_{2}$, which can be strongly interrupted by catalase (5).

Perfusion experiment with exogenously generated reaction products

The precipitate produced artificially did not adhere closely and evenly to the plasma membrane, whether it was present on the cell surface or in the vacuoles. This finding shows that distribution of the precipitate is quite different from that occurring in the endogenous $\mathrm{H}_{2} \mathrm{O}_{2}$ generation system (5).

Regarding the in situ localization of reaction products, considerable evidence demonstrates that superoxide anion and successive hydroperoxide production take place on the outer surface of the cell membrane which is then invaginated to form phagocytic vacuoles $(1,4,9,22)$, showing here a bactericidal function or detoxifying action. Our findings are well consistent with this evidence. However, in our experiments, little or only scattered cerous precipitate was observed on the inner surface of the phagocytic vacuoles containing a large or small amount of LPS. A clear explanation for this is impossible now, but the following two possibilities may be considered; that is, $\mathrm{CeCl}_{3}$ is unable to easily penetrate into reactive sites (5), or $\mathrm{H}_{2} \mathrm{O}_{2}$ is more or less consumed as a result of $\mathrm{H}_{2} \mathrm{O}_{2}$ or $\mathrm{O}_{2}^{-}$reacting with LPS instead of $\mathrm{CeCl}_{3}$.

There is another problem on which we will comment here. This is on the finding that free reaction products without adherence to the plasma membrane occurred frequently in the sinusoidal lumen. The question is whether this was the result of real enzyme activity or not. On detailed observation, it was found that the amount of free products usually paralleled the amount of those closely adherent to the cell membrane under various experimental conditions. Therefore, the following possibilities should be considered: That the precipitate was freed from the surface of the cell membrane after the reaction occurred in situ; or that $\mathrm{H}_{2} \mathrm{O}_{2}$ or $\mathrm{O}_{2}^{-}$ itself was freed from the cell membrane where it was just generated $(2,6,15,19)$ and the reaction occurred thereafter.

In conclusion, it should be specially emphasized that the endothelial cells, in addition to the Kupffer cells, are found to have a real $\mathrm{H}_{2} \mathrm{O}_{2}$ generation system dependent on NADPH. This reaction occurred especially on the membrane surface of the coated pits and vesicles, as well as on the extensive interface between a pair of cell membranes of the endothelial cells which were closely connected with each other. All these findings suggest that they may be likewise responsible to a defensive activity.

In comparing the findings between the ICR/d-strain and the Jcl : Wistar-strain (normal controls), it is clear that $\mathrm{H}_{2} \mathrm{O}_{2}$ generation observed in the sinusoidal lining cells of the former is kept in an enhanced condition, perhaps due to constitutional 
defects of the defense mechanisms as represented by frequent occurrence of dermatitis and/or pneumonia (13). It has been also found that this rat strain has a clear tendency to succumb to liver shock when small amounts of LPS are injected intraperitoneally, e.s. $0.3 \mathrm{mg} / \mathrm{kg}$ level (11).

\section{ACKNOWLEDGEMENT}

The authors wish to thank Prof. Ryuei Maeda for his continuous encouragement and support.

\section{REFERENCES}

1. Babior, B. M.: Oxygen-dependent microbial killing by phagocytosis. New Eng. J. Med. 298; 659-668, 1978.

2. Babior, B. M., Curnutte, J. T. and McMurrich, B. J.: The particulate superoxide-forming system from human neutrophils. Properties of the system and further evidence supporting its participation in the respiratory burst. J. Clin. Invest. 58; 989-996, 1976.

3. Babior, B. M., Kipnes, R. S. and Curnutte, J. T.: Biological defense mechanisms. The production by leukocytes of superoxide, a potential bactericidal agent. J. Clin. Invest. 52; 741-744, 1973.

4. Babior, G. L., Rosin, R. E., McMurrich, B. J., Peters, W'. A. and Babior, B. M.: Arrangement of the respiratory burst oxidase in the plasma membrane of the neutrophil. J. Clin. Invest. 67; 1724-1728, 1981 .

5. Briggs, R. T., Drath, D. B., Karnovsky, M. L. and Karnovsky, M. J.: Localization of NADH oxidase on the surface of human polymorphonuclear leukocytes by a new cytochemical method. J. Cell Biol. 67; 566-586, 1975.

6. Curnutte, J. T. and Babior, B. M.: Biological defense mechanisms. The effect of bacteria and serum on superoxide production by granulocytes. J. Clin. Invest. 53; 1662-1672, 1974.

7. Curnutte, J. T. and Babior, B. M.: Effect of anerobiosis and inhibitors on $\mathrm{O}_{2}^{-}$production by human granulocytes. Blood; J. Hematol. 45; 851-861, 1975.

8. Funo, S.: NADPH oxidase activity in Kupffer and endothelial cells of liver from ICR-strain rat using an organ perfusion system, -comparison with $\mathrm{Jcl}$ :Wistar-strain rat-. J. Jap. Soc. R. E. S. 23; 271-291, 1983. (in Japanese)

9. Goldstein, I. M., Cerqueira, M., Lind, S. and Kaplan, H. B.: Evidence that the superoxidegenerating system of human leukocytes is associated with the cell surface. J. Clin. Invest. 59; 249-254, 1977.

10. Hirai, K., Ueno, S. and Ogawa, K.: Plasma membrane-associated NAD(P)H oxidase and superoxide dismutase in pulmonary macrophages. Acta histochem. cytochem. 13;113-126, 1980.

11. Ihara, N., Funo, S. and Yamamoto, R.: Histochemical and electron-microscopical studies on rat liver administered with endotoxin, - comparison between cataractous rat of ICR-strain and the other strains - (Oral report at the 80th academic conference of Kansai Medical University). J. Kansai Med. L'niv'. 34;685, 1982. (in Japanese)

12. Ihara, N.: A new strain of rat with an inherited cataract, Experientia 39; 909-911, 1983.

13. Ihara, N.: Occurrence of early thymus atrophy and the skin lesions observed in the cataractous rat of ICR/d-strain. J. Kansai .Med. Univ. 36(3); 575-581, 1959.

14. Iyer, G. Y. N., Islam, M. F. and Quastel, J. H.: Biochemical aspects of phagocytosis. Nature $192 ; 535-541,1961$.

15. Kakinuma, K.: Metabolic alterations in phagocytosis. In Leukocytes and Phagocytosis, 2nd Ed., ed. by S. Minakami and K. Kakinuma, Kodansya Scientific, Tokyo, 1981, p. 93. (In Japanese)

16. Nakamura, M., Baxter, C. R. and Masters, B.S.S.: Simultaneous demonstration of phagocyto- 
sisconnected oxygen consumption and corresponding NAD $(\mathrm{P}) \mathrm{H}$ oxidase activity: Direct evidence for NADPH as the predominant electron donor to oxygen in phagocytizing human neutrophils. Biochem. Biophys. Res. Commun. 98; 743-751, 1981.

17. Nakamura, M. and Minakami, S.: Biochemistry of microbicidal mechanism, with special reference to oxygen-dependent microbicidal action. Clinical Immunology 14;940-950, 1982. (in Japanese)

18. Rossi, F., Romeo, D. and Patriarca, P.: Mechanism of phagocytosis-associated oxidative metabolism in polymorphonuclear leukocytes and macrophages. J. Reticuloendothel. Soc. 12; 127-149, 1972.

19. Root, R. K. and Metcalf, J. A.: $\quad \mathrm{H}_{2} \mathrm{O}_{2}$ release from human granulocytes during phagocytosis. Relationship to superoxide anion formation and cellular catabolism of $\mathrm{H}_{2} \mathrm{O}_{2}$ : Studies with normal and cytochalasin B-treated cells. J. Clin. Invest. 60; 1266-1279, 1977.

20. Sbarra, A. J. and Karnovsky, M. L.: The biochemical basis of phagocytosis. I. Metabolic changes during the ingestion of particles by polymorphonuclear leukocytes. J. Biol. Chem. $234 ; 1355-1362,1959$.

21. Sugano, T., Suda, K., Shimada, M. and Oshino, N.: Biochemical and ultrastructural evaluation of isolated rat liver systems perfused with a hemoglobin-free medium. J. Biochem. $83 ; 995-1007,1978$.

22. Van Berkel, T.J. C. and Kruijt, J. K.: Distribution and some properties of NADPH and NADH oxidase in parenchymal and nonparenchymal liver cells. Arch. Biochem. Biophys. 179; 8-14, 1977 . 